\title{
Amaryllidaceae alkaloids with anti-Trypanosoma cruzi activity
}

\author{
Nieves Martinez-Peinado ', Nuria Cortes-Serra ${ }^{1}$, Laura Torras-Claveria², Maria-Jesus Pinazo ${ }^{1}$, Joaquim Gascon ${ }^{1}$, \\ Jaume Bastida ${ }^{2}$ and Julio Alonso-Padilla ${ }^{1{ }^{*}(\text { D }}$
}

\begin{abstract}
Background: Chagas disease, caused by the protozoan Trypanosoma cruzi, is a neglected disease that affects $\sim 7$ million people worldwide. Development of new drugs to treat the infection remains a priority since those currently available have frequent side effects and limited efficacy at the chronic stage. Natural products provide a pool of diversity structures to lead the chemical synthesis of novel molecules for this purpose. Herein we analyzed the anti-T. cruzi activity of nine alkaloids derived from plants of the family Amaryllidaceae.

Methods: The activity of each alkaloid was assessed by means of an anti-T. cruzi phenotypic assay. We further evaluated the compounds that inhibited parasite growth on two distinct cytotoxicity assays to discard those that were toxic to host cells and assure parasite selectivity.

Results: We identified a single compound (hippeastrine) that was selectively active against the parasite yielding selectivity indexes of 12.7 and 35.2 against Vero and HepG2 cells, respectively. Moreover, it showed specific activity against the amastigote stage $\left(I C_{50}=3.31 \mu \mathrm{M}\right)$.
\end{abstract}

Conclusions: Results reported here suggest that natural products are an interesting source of new compounds for the development of drugs against Chagas disease.

Keywords: Chagas disease, Trypanosoma cruzi, Alkaloids, Amaryllidaceae, Hippeastrine, Phenotypic assays, Cytotoxicity

\section{Background}

Chagas disease (or American trypanosomiasis) is a neglected infectious disease caused by the protozoan parasite Trypanosoma cruzi (order Kinetoplastida; family Trypanosomatidae). It is estimated that $\sim 7$ million people are affected by the disease, mainly in Latin America where T. cruzi infection is endemic [1].

The disease progresses in two phases. There is first a short acute phase that is usually asymptomatic and thus goes unnoticed. This is followed by a chronic phase characterized by absent or slow progression of clinical

*Correspondence: julio.a.padilla@isglobal.org

1 Barcelona Institute for Global Health (ISGlobal), Hospital Clínic University of Barcelona, 08036 Barcelona, Spain

Full list of author information is available at the end of the article manifestations [2]. Nonetheless, it is estimated that $~ 40 \%$ of those chronically infected will ultimately develop disruptive damage to the heart and/or digestive tract (esophagus and colon) tissues, which can lead to the formation of mega-syndromes and death if untreated $[2,3]$.

Since the 1970s only two drugs have been available to treat $T$. cruzi infections: benznidazole (BNZ) and nifurtimox (NFX) [1]. Both have good efficacy and tolerability when administered to infected new-borns [4]. But their efficacy diminishes at the chronic stage, which is usually diagnosed at adulthood with serological tests that detect specific anti-T. cruzi type G immunoglobulins [1]. Moreover, both drugs have long regimens of administration that entail the advent of frequent adverse events which often drive to treatment discontinuation [5-7]. There

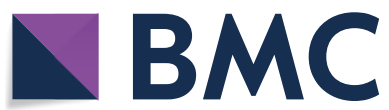

(c) The Author(s) 2020. This article is licensed under a Creative Commons Attribution 4.0 International License, which permits use, sharing, adaptation, distribution and reproduction in any medium or format, as long as you give appropriate credit to the original author(s) and the source, provide a link to the Creative Commons licence, and indicate if changes were made. The images or other third party material in this article are included in the article's Creative Commons licence, unless indicated otherwise in a credit line to the material. If material is not included in the article's Creative Commons licence and your intended use is not permitted by statutory regulation or exceeds the permitted use, you will need to obtain permission directly from the copyright holder. To view a copy of this licence, visit http://creativeco mmons.org/licenses/by/4.0/. The Creative Commons Public Domain Dedication waiver (http://creativecommons.org/publicdomain/ zero/1.0/) applies to the data made available in this article, unless otherwise stated in a credit line to the data. 
is thus an urgent unmet need of safer and more efficacious drugs for the treatment of chronic Chagas disease, for which natural products may represent a promising approach to discover new lead compounds [8-10].

In this regard, members of the family Amaryllidaceae have attracted considerable attention in the last few years due to their unique alkaloid composition with multiple biological activities [11]. Amaryllidaceae plants have been studied for their potential application as a source of anticancer, anti-inflammatory, antimicrobial, anti-parasitic and anticholinesterase activities [12]. In fact, they have been used for centuries as part of traditional treatments for fever, swelling, cancer or malaria [12]. Remarkably, in 2001 the Food and Drug Administration (FDA) approved the use of galanthamine (trade name Razadyne), an alkaloid identified from the Amaryllidaceae plant Galanthus woronowi, to treat Alzheimer's disease [13].

Alkaloid constituents found in these plants are classified in eight groups based on structure and biogenesis from the common precursor $O$-methylnorbelladine: galanthamine; lycorine; crinine; haemanthamine; homolycorine; narciclasine; tazettine; and montanine [14]. The unique structure of this set of alkaloids provides a viable platform for phytochemical-based drug discovery [8]. With the aim to identify prospective drug development starting points that could eventually become new therapeutic solutions for Chagas disease we have adapted an in vitro anti-T. cruzi phenotypic assay based on the parasite Tulahuen strain engineered to express a bacterial $\beta$-galactosidase gene [15] and green monkey epithelial cells (Vero) as hosts. We evaluated the anti-T. cruzi activity of nine crystalized alkaloid compounds extracted from members of the Amaryllidaceae family: lycorine, hippeastrine, crinine, haemanthamine, narciclasine, tazettine, montanine, sanguinine and 1-O-acetylcaranine (Fig. 1) [16]. In all the assays performed we always included the standard anti-parasitic drug BNZ for comparison.

In order to unveil the specific T. cruzi growth inhibitory capacity of those compounds that were found active in the anti-parasitic assay, we further used two secondary biological assays to determine the compounds' level of cytotoxicity. These were respectively based on the same host Vero cells and in the human hepatocellular carcinoma cell line HepG2. Finally, we determined the anti-amastigote specific activity of the only compound that was revealed to hold selective anti-parasitic activity. Results obtained were particularly promising for the compound hippeastrine from Narcissus cv. Salome [17] and they are discussed herein.

\section{Methods}

Collection of purified alkaloid compounds from Amaryllidaceae plants

Lycorine, hippeastrine, crinine, haemanthamine, narciclasine, tazettine, montanine, sanguinine and 1-O-acetylcaranine alkaloids were isolated from extracts of different Narcissus species [16, 18]. The information of all the compounds studied can be found in the extensive chapter by Bastida et al. [16]. In brief, the procedure followed to identify the alkaloids within the corresponding plant extract was as follows: plant material $(60 \mathrm{mg})$ was macerated with $\mathrm{MeOH}$; the mix was filtered and the solvent evaporated to dryness. After that, extracts were acidified with $500 \mu \mathrm{l}$ of $\mathrm{H}_{2} \mathrm{SO}_{4}(2 \%, \mathrm{v} / \mathrm{v})$. The neutral material was removed with diethyl ether and basified with 200 $\mu \mathrm{l} \mathrm{NH} \mathrm{N}_{4} \mathrm{OH}(25 \%, \mathrm{v} / \mathrm{v})$. Then, $750 \mu \mathrm{l}$ of diethyl ether was added to separate the organic phase, this was repeated twice, and the solvent evaporated to dryness. All compounds were crystals, obtained after three successive crystallization rounds to ensure maximum purity. They were subjected to a combination of chromatographic techniques and alkaloids were identified by GC-MS and NMR [16, 17] (Additional file 1: Figures S1, S2). In order to obtain milligrams of product, the corresponding scaleup was performed as previously described $[19,20]$.

\section{Host cells cultures}

Vero (green monkey kidney epithelial cells), LLC-MK2 (Reshus monkey kidney epithelial cells) and HepG2 (human liver epithelial cells) cultures were maintained with DMEM supplemented with $1 \%$ penicillin-streptomycin (100 units/ml of penicillin and $100 \mu \mathrm{g} / \mathrm{ml}$ of streptomycin; P-S) and 10\% heat inactivated fetal bovine serum (FBS) at $37{ }^{\circ} \mathrm{C}, 5 \% \mathrm{CO}_{2}$ and $>95 \%$ humidity as described by Buckner et al. [15]. HepG2 were also supplemented with $1 \times$ non-essential amino acids (ref. 01-3401B; Biological Industries, Beit-Haemek, Israel).

\section{Culture of T. cruzi parasites}

Trypanosoma cruzi parasites from the Tulahuen strain (discrete typing unit, DTU VI) expressing $\beta$-galactosidase were kindly provided by Dr Fred Buckner (University of Washington, Seattle, USA) and maintained using LLC-MK2 cells as hosts in DMEM supplemented with $2 \%$ FBS and $1 \%$ P-S as previously described [15]. Free-swimming trypomastigotes were purified by centrifugation of the cell culture supernatant for $7 \mathrm{~min}$ at $2500 \times \mathrm{rpm}$ using a low break speed, then allowing them to swim out of the pellet [21]. Purified trypomastigotes were used to keep the parasite 
cycle in LLC-MK2 cells and for the performance of the anti-parasitic assays. In the last case, an extra round of centrifugation was performed to remove phenol red from the maintenance DMEM and replace with a phenol red-free DMEM medium, which was supplemented with $1 \% \mathrm{P}$-S-glutamine, $2 \% \mathrm{FBS}, 1 \mathrm{mM}$ sodium-pyruvate and $25 \mathrm{mM}$ HEPES [21].

\section{Assay to detect $T$. cruzi growth inhibition in 96-well plates}

Our assay is based on Vero cells as hosts and infective trypomastigotes from the Tulahuen strain that express the bacterial $\beta$-galactosidase enzyme as reporter activity [15]. First, alkaloids were added in the first column of a 96-well tissue culture treated plates at an initial concentration of $100 \mu \mathrm{M}$ and diluted in assay medium into the next columns of the plate to conform doseresponse plate-maps following either a 1:2 or 1:3 fold pattern. Then, Vero cells were detached from their growing flasks, counted and diluted at a concentration of $1 \times 10^{6}$ cells per ml. Trypan blue staining was used to check their viability, which had to be $>95 \%$ to proceed. In conjunction, purified trypomastigotes were counted and diluted at a concentration of $1 \times 10^{6}$ cells per $\mathrm{ml}$. We directly mixed Vero cells and trypomastigotes in a falcon tube in a sufficient volume so as to add $100 \mu \mathrm{l}$ of the mix per well $(50,000$ Vero cells and 50,000 trypomastigote cells per well; with the multiplicity of infection, MOI =1). The percentage of DMSO in all wells was always kept below $0.5 \%$.

The reference drug BNZ was used as a control of drug growth inhibition in each run, whereas each plate contained its own negative (maximum parasite growth; Vero cells plus parasites without drugs) and positive (minimum parasite growth; trypomastigote forms alone marking an enzymatic zero time or baseline<smiles></smiles>

Lycorine

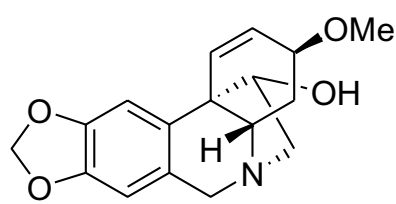

Haemanthamine

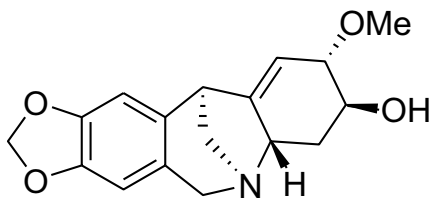

Montanine<smiles>CN1CCC2=C[C@H](O)[C@H]3OC(=O)c4cc5c(cc4[C@H]3[C@H]21)OCO5</smiles>

Hippeastrine<smiles></smiles>

Narciclasine<smiles>CN1CCC23C=CC(O)CC2Oc2c(O)ccc(c23)C1</smiles>

Sanguinine<smiles>O[C@@H]1C=CC23CCN(Cc4cc5c(cc42)OCO5)CC13</smiles>

Crinine<smiles></smiles>

Tazettine

Fig. 1 Chemical structures of the alkaloids evaluated in this study 
galactosidase activity) controls. Note that trypomastigotes are unable to multiply in the absence of susceptible host cells. Plates were incubated for 4 days at $37^{\circ} \mathrm{C}$ [21], with the readout performed by adding $50 \mu \mathrm{l}$ per well of a PBS solution containing $0.25 \%$ NP40 and 500 $\mu \mathrm{M}$ chlorophenol red- $\beta$-D-galactoside (CPRG) substrate, as previously described [21]. Upon addition of the substrate, plates were further incubated at $37{ }^{\circ} \mathrm{C}$ for another $4 \mathrm{~h}$ and the absorbance read out at 590 $\mathrm{nm}$ using an Epoch Gene5 spectrophotometer (Biotek, Winooski, USA). All experiments were performed at least in triplicate.

\section{Anti-amastigote specific activity of progressed compound (hippeastrine)}

Using Vero cells as hosts and the recombinant T. cruzi strain expressing $\beta$-galactosidase, we further adapted the anti-parasitic assay described above to determine whether the anti-parasitic activity was specific against the intracellular amastigote forms. In brief, we plated 50,000 Vero cells per well in a 96-well plate and allowed them to attach for $1.5 \mathrm{~h}$. Then, we infected the monolayers with 50,000 purified trypomastigotes per well $(\mathrm{MOI}=1)$ that were allowed for $1 \mathrm{~h}$ to adsorb and enter the cells before being washed with PBS three times. Finally, assay medium was added and used to dilute hippeastrine and BNZ in a dose-response pattern. In each plate we included the same controls as for the anti-T. cruzi assay. Test plates were incubated for $96 \mathrm{~h}$ and the assay readout was performed as described above.

\section{Toxicity assays with Vero and HepG2 cells}

For the cell toxicity assays, compounds were added to tissue culture treated 96-well plates following a doseresponse dilution pattern, $1: 2$ or $1: 3$, with a starting concentration of $400 \mu \mathrm{M}$ or $800 \mu \mathrm{M}$ per well in the first column of the plate. Cell viability was checked upon cell counting with Trypan blue and we only proceeded if viability was $>95 \%$. Vero cell suspension was diluted at a concentration of $5 \times 10^{5}$ cells per $\mathrm{ml}$ before adding 100 $\mu l$ per well. In the case of HepG2 cells, we used a dilution of $3.2 \times 10^{4}$ cells per ml. Each test plate or run contained its own negative (untreated cells) and positive (medium alone) controls. Plates were incubated at $37{ }^{\circ} \mathrm{C}$ for 4 days in the case of Vero cells, and 2 days for HepG 2 cells. We then added $50 \mu \mathrm{l}$ per well of a PBS solution containing $10 \%$ Alamar Blue reagent (Thermo Fisher Scientific, Eugene, USA) and incubated the plates for $6 \mathrm{~h}$ at $37{ }^{\circ} \mathrm{C}$ before reading the fluorescence intensity in a Tecan Infinite $\mathrm{M} \mathrm{Nano}^{+}$reader (Tecan, Männedorf, Switzerland) (excitation: $530 \mathrm{~nm}$, emission: $590 \mathrm{~nm}$ ). The percentage of DMSO in all wells was always kept below 0.5\%. All experiments were performed at least in triplicate.

\section{Data analysis}

Absorbance and fluorescence values derived from the anti-T. cruzi and cell toxicity assays were normalized to the controls [22]. $\mathrm{IC}_{50}$ and $\mathrm{TC}_{50}$ values were determined using GraphPad Prism 7 software (version 7.00, 2016) using a non-linear regression analysis model defined by the equation:

$$
Y=100 \div\left(\left(1+X^{\text {Hillslope }}\right) \div\left(\text { IC } 50^{\text {Hillslope }}\right)\right)
$$

These $\mathrm{IC}_{50}$ and $\mathrm{TC}_{50}$ values are the compound concentrations capable of inhibiting growth of parasites and cells by $50 \%$, respectively. $Z$ '-values were calculated as described previously [23]. Values provided are the mean and standard deviation (SD) of at least three independent experiments.

\section{Results and discussion}

Quality assessment of the anti-T. cruzi and cell toxicity assays

As part of the process of setting up the biological assays we calculated their Z' parameter to assess reproducibility and statistical robustness [23]. In general, assays with a $Z$ ' between 0.5 and 1 are considered appropriate for the screening of compounds [23]. Remarkably, our anti-parasitic assay had a very good performance and its $Z$ '-value remained consistently $>0.5$ with an average value of 0.89 (0.097) (Fig. 2a). Regarding the two cytotoxicity assays used in this study, we retrieved $Z^{\prime}=0.76(0.067)$ for the assay based on Vero cells, and a $Z^{\prime}=0.73(0.054)$ for the assay based on HepG2 cells (Fig. 2c-e).

Additionally, in every run of the T. cruzi growth inhibition assay and Vero cell toxicity assay performed, we included the reference drug BNZ as a control, whereas the reference drug digitoxin (DTX) [24] was included in all the HepG2 cells toxicity assays. Overall, averaged $\mathrm{IC}_{50}$ and $\mathrm{TC}_{50}$ values for BNZ were $1.56(0.39) \mu \mathrm{M}$ and 173.4 (43.57) $\mu \mathrm{M}$, respectively (Fig. 2b-d, Additional file 1: Figure S3), which correlates with previous reports [21, 25]. The digitoxin $\mathrm{TC}_{50}$ mean value in the HepG2 cell assay was 0.29 (0.14) $\mu \mathrm{M}$ (Fig. 2f, Additional file 1: Figure S3).

\section{Anti-T. cruzi activity of the alkaloids extracted from Amaryllidaceae}

As in other widely used anti-T. cruzi assays $[21,22,26]$ we relied on the genetically robust $T$. cruzi Tulahuen strain expressing beta-galactosidase activity as a surrogate of parasite growth [15]. However, because the amastigote replicative stage of $T$. cruzi is obligatory intracellular, 

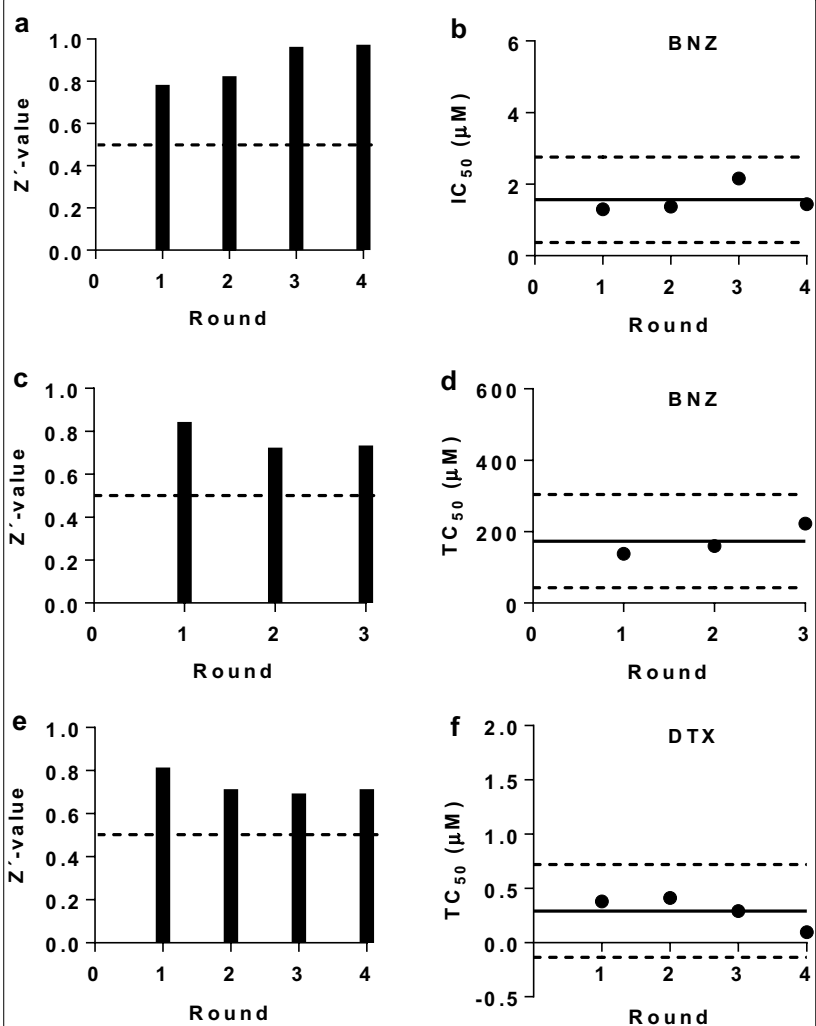

Fig. 2 Quality controls of the T. cruzi growth inhibition assay $(\mathbf{a}, \mathbf{b})$, toxicity assay with Vero cells $(\mathbf{c}, \mathbf{d})$ and toxicity assay with HepG2 cells $(\mathbf{e}, \mathbf{f})$. Z'-values for each of the rounds launched are represented on the left $(\mathbf{a}, \mathbf{c}, \mathbf{e})$; dashed line marks the 0.5 threshold. $\mathrm{IC}_{50}$ and $\mathrm{TC}_{50}$ values of the reference drugs BNZ and DTX are represented on the right $(\mathbf{b}, \mathbf{d}, \mathbf{f})$; continuous lines indicate the average values, whereas the dashed lines indicate \pm 3 SD limits

our assay relied on Vero cells as hosts. Notably, Vero cells have been described to be deficient in interferon response due to a mutation in the simian interferon beta gene [27], which makes them more susceptible to infection and thereby a good system for the discovery of active compounds against T. cruzi.

Results obtained from the phenotypic T. cruzi growth inhibition assay revealed that lycorine, hippeastrine, haemanthamine, narciclasine and montanine were active, while crinine, tazettine, sanguinine and 1-O-acetylcaranine were inactive against the parasite (Fig. 3). Tazettine, sanguinine and 1-O-acetylcaranine have been described as poor antiprotozoal agents before [28, 29]. Nonetheless, Machocho et al. [28] described that compound 3-O-acetylsanguinine had some activity $\left(\mathrm{IC}_{50}=2.3 \mu \mathrm{g} / \mathrm{ml}\right.$; i.e. $7.29 \mu \mathrm{M})$ against trypomastigotes from the T. cruzi strain Tulahuen C4. Although different phenotypic anti-T. cruzi assays were performed in each case, the results obtained by these authors could suggest that the presence of an acetyl group might increase the anti-T. cruzi activity of sanguinine.

On the other hand, crinine and haemanthamine are crinane-type alkaloids that belong to the $\beta$-crinane and $\alpha$-crinane subgroups, respectively [30]. Other studies evaluating the anti-parasitic potential of alkaloids have reported that the presence of a methylene-dioxi group seemed to favour a more potent anti-parasitic activity [31]. This could be the explanation for the different antiT. cruzi activities observed by us between these two crinane-type alkaloids.

The highest anti-T. cruzi activity rates were yielded by lycorine $\left[\mathrm{IC}_{50}=0.70(0.018) \mu \mathrm{M}\right]$ and narciclassine $\left[\mathrm{IC}_{50}=0.495(0.018) \mu \mathrm{M}\right]$, which exceeded in potency that of the reference drug BNZ (Table 1, Additional file 1: Figure S3). Lycorine was the first alkaloid described from the plant family Amaryllidaceae and one of the most commonly found amongst genera in the family [32]. Lycorine extracted from Crinum stuhlmannii, Zhepyranthes citrina and Narcissus broussonetii has previously been tested against T. cruzi [33-35]. However, in contrast to our results, it was described as inactive against the parasite; a feature that could be explained due to the use of different assays. It has been reported that major differences in the activity of compounds can be found depending on the host cell line and the biological assay used [36]. In this respect, previous studies relied on the use of L6 cells as a host, whereas we have used Vero cells. Lycorine and 1-O-acetylcaranine belong to the lycorine group but structurally differ in two positions of the overall structure (Fig. 1). In this case, the anti-parasitic activity is increased with the substitution of a hydrogen and an acetoxy group per two hydroxyl groups.

Narciclasine yielded the most potent activity against T. cruzi in this study (Table 1). To the best of our knowledge, this compound has not been tested against T. cruzi before. Likewise, there are no previous reports on the anti-T. cruzi activity of montanine, also shown for the first time in this study. Montanine and haemanthamine showed average $\mathrm{IC}_{50}$ values similar to that of $\mathrm{BNZ}$, respectively $1.99(0.089) \mu \mathrm{M}$ and $1.59(0.062) \mu \mathrm{M}$ versus $1.56(0.070) \mu \mathrm{M}$ of BNZ (Table 1. Additional file 1: Figure S3). Osorio et al. [29] have previously described the high activity of haemanthamine against $T$. cruzi $\left(\mathrm{IC}_{50}=1.8 \mu \mathrm{g} /\right.$ ml; i.e. $5.97 \mu \mathrm{M})$.

Finally, we found that hippeastrine was the active alkaloid with a higher $\mathrm{IC}_{50}$ value $\left[\mathrm{IC}_{50}=3.63(0.24) \mu \mathrm{M}\right]$. Its activity was lower than that of BNZ, but still fell within a range five times the $\mathrm{IC}_{50}$ of the standard drug (Table 1 , Additional file 1: Figure S3). Hippeastrine was first isolated from the Amaryllidaceae plant Lycoris radiata and has been reported to exhibit activity against avian influenza virus $\left.\mathrm{H} 5 \mathrm{~N} 1 \mathrm{IC}_{50}=47.5(0.37) \mu \mathrm{M}\right]$ [37]. Moreover, 
promising results against ZIKA virus infection have recently been reported with hippeastrine hydrobromide [38]. This was shown to remove ZIKA virus from infected human neural progenitors, recover a ZIKV-induced microcephaly phenotype in human forebrain organoids and even suppress virus propagation in infected adult mice [38]. Antiviral [37, 38], antibacterial and antifungal [39] activities have been reported for hippeastrine, despite this, little information is available about its antiparasitic activity. Cedron et al. [40] tested 21 hippeastrine derivatives that included functional group transformations, structural simplification and dimer formation against Plasmodium falciparum (strain F-32 Tanzania). The anti-malarial activity increased by 10 -fold when dimers were evaluated compared to the single alkaloid activity, suggesting an improved binding to the related target or the hydrolysis of the dimer onto two molecules [40]. To our knowledge, this is the first time that anti-T. cruzi activity is reported for hippeastrine. Results reported by Cedron et al. [40] would suggest to further pursue research with hippeastrine derivatives against $T$. cruzi.

Identification of alkaloid compounds with specific anti-T. cruzi activity

With the aim of further selecting those alkaloids with specific activity against the parasite and discard those that were toxic to host cells, we used two secondary cell toxicity assays with monkey (Vero) and human (HepG2) cells. Since the compounds activity might vary depending on the characteristics of the cell line used, performing the cytotoxicity assay in two cell lines will provide a more robust readout. Moreover, HepG2 cells are a widespread cellular model used to anticipate potential liver toxicity of drug metabolism [41, 42]. We determined a selectivity index (SI; or $\mathrm{TC}_{50}$ to $\mathrm{IC}_{50}$ ratio) $>10$ to consider whether an alkaloid was suitable for further progression, as described elsewhere [22].
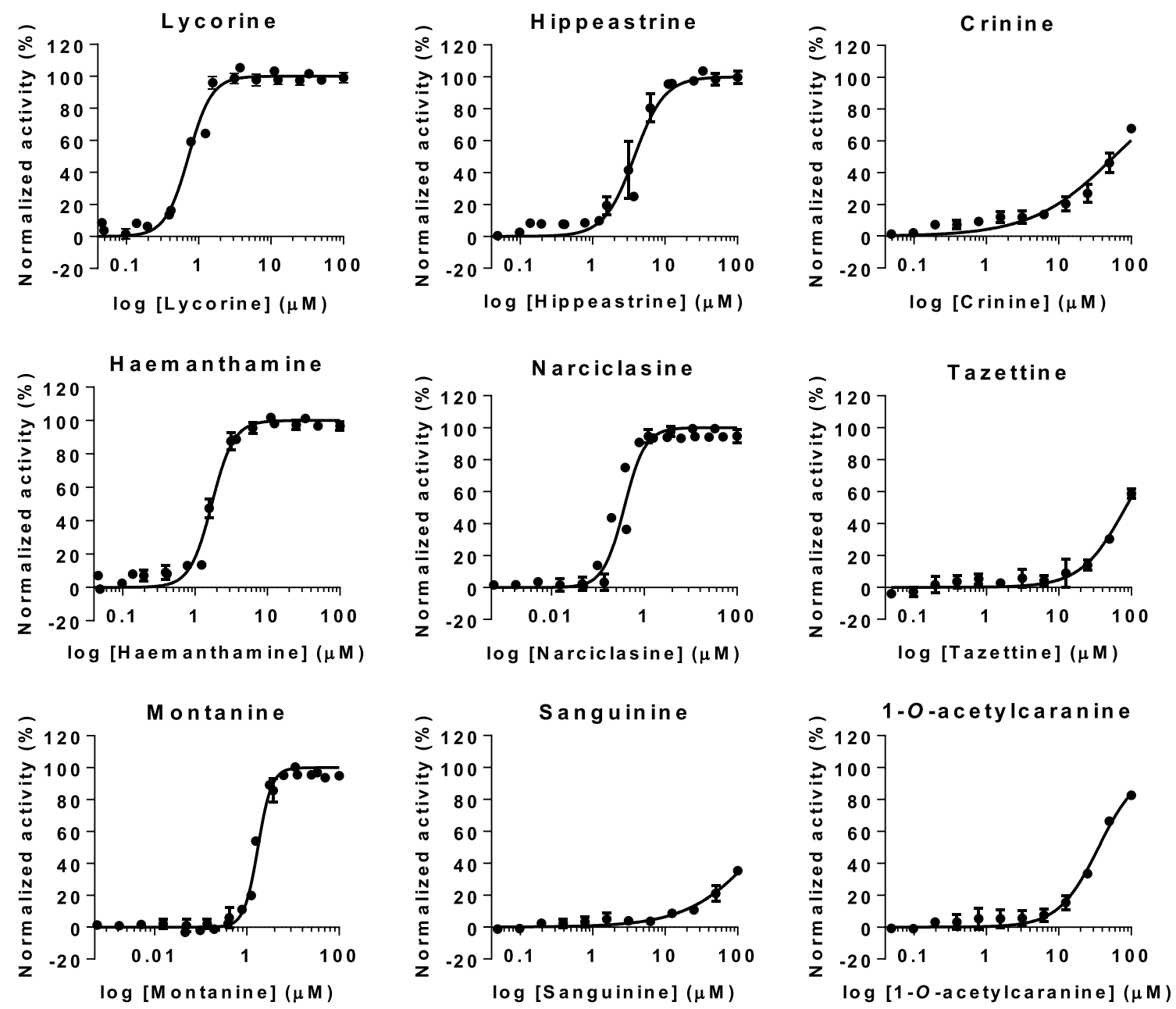

Fig. 3 Anti-T.cruzi phenotypic assay dose-response curves. Graphs represent mean results and SD of at least three biological replicates 
Table 1 Alkaloid average $\mathrm{IC}_{50}, \mathrm{TC}_{50}$ and $\mathrm{SI}$ values for Vero and HepG2 cells

\begin{tabular}{llllll}
\hline Alkaloid & $\mathrm{IC}_{50}(\mu \mathrm{M})$ & $\mathrm{TC}_{50}(\mu \mathrm{M})^{\mathrm{a}}$ & $\mathrm{Sl}^{\mathrm{a}}$ & $\mathrm{TC}_{50}(\mu \mathrm{M})^{\mathrm{b}}$ & $\mathrm{SI}^{\mathrm{b}}$ \\
\hline BNZ & 1.56 & 173.4 & 111.15 & 168.76 & 108.18 \\
Lycorine $^{-5.56}$ & 0.70 & 5.21 & 7.44 & 21.87 & 31.24 \\
Hippeastrine & 3.63 & 45.99 & 12.67 & 128.10 & 35.29 \\
Crinine & 57.93 & - & & - & \\
Haemanthamine & 1.59 & 11.52 & 7.25 & 42.48 & 26.72 \\
Narciclasine & 0.49 & 0.66 & 1.33 & 2.73 & 5.52 \\
Tazettine & 83.03 & - & & - & \\
Montanine & 1.99 & 5.04 & 2.53 & 46.10 & 23.17 \\
Sanguinine & 213.40 & - & & - & \\
1-O-acetylcaranine & 35.49 & - & & - &
\end{tabular}

a Vero cell toxicity assay

${ }^{\text {b }}$ HepG2 cell toxicity assay

c The only alkaloid evaluated in this study that showed specific anti-T. cruzi activity

Note: The standard drug BNZ is included in the first line for comparison

Thereafter, all the alkaloids reported as active against T. cruzi were analysed through both cell toxicity assays. All of them were more toxic to Vero cells than to HepG2 cells (Fig. 4). The cytotoxicity values registered against
Vero and HepG2 cells indicated that narciclasine activity was not specific against $T$. cruzi, as it respectively showed $\mathrm{TC}_{50}=0.66(0.082) \mu \mathrm{M}$ against Vero cells, and $\mathrm{TC}_{50}=2.73(0.67) \mu \mathrm{M}$ against HepG2 cells, resulting in a $\mathrm{SI}<10$ in both cases (Table 1). In addition, montanine with a $\mathrm{SI}=2.53$ in relation to Vero cells was not specific to T. cruzi either (Table 1), even though it showed low toxicity to HepG2 cells $\left[\mathrm{TC}_{50}=46.1(11.99) \mu \mathrm{M}\right]$ (Table 1). Something similar occurred with lycorine, which was weakly active against HepG2 cells $\left[\mathrm{TC}_{50}=21.87\right.$ (4.16) $\mu \mathrm{M}$ ] (Table 1). Lycorine presented a SI versus this cell line over ten times its registered anti-T. cruzi activity, but turned to be toxic to Vero cells $\left[\mathrm{TC}_{50}=5.21(0.80) \mu \mathrm{M}\right]$ with a $\mathrm{SI}<10$ and thus was discarded from further progression (Table 1). We generally observed an increase sensitivity of Vero cells to the alkaloids when compared to HepG2 cells. This may have been in part due to the fact that compounds were incubated for a longer time (four versus two days) on Vero cells than on HepG2 cells.

Haemanthamine has been reported to present a $\mathrm{TC}_{50}=13 \mu \mathrm{g} / \mathrm{ml}$, i.e. $43.14 \mu \mathrm{M}$ for HepG2 cells [43], which correlates with the $\mathrm{TC}_{50}$ value obtained in our study with the same cell line $\left[\mathrm{TC}_{50}=42.48(6.96) \mu \mathrm{M}\right]$ (Table 1). However, although this compound showed a SI $>10$ with respect to HepG2 cells, when evaluated on

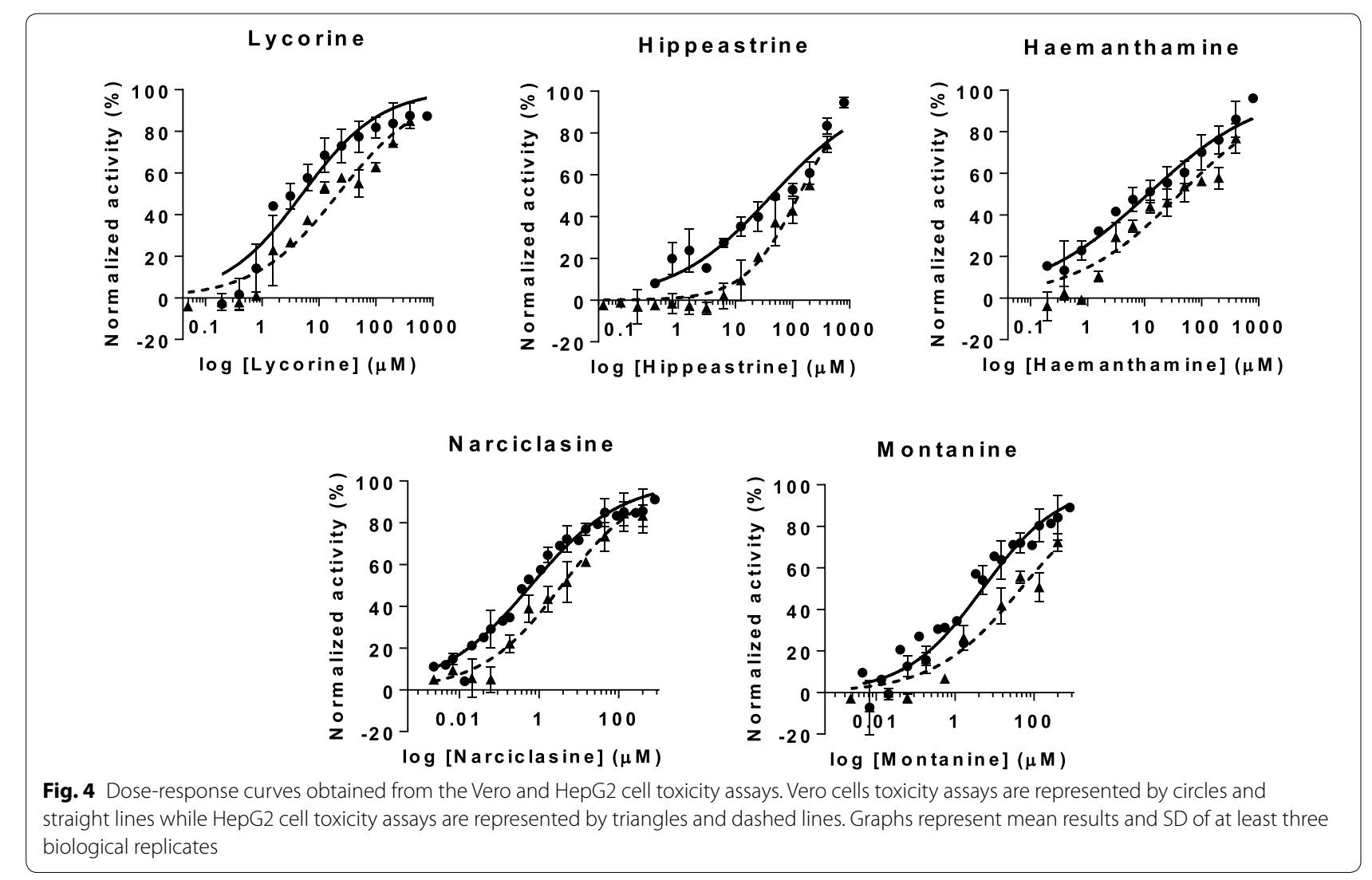




\section{B N Z}

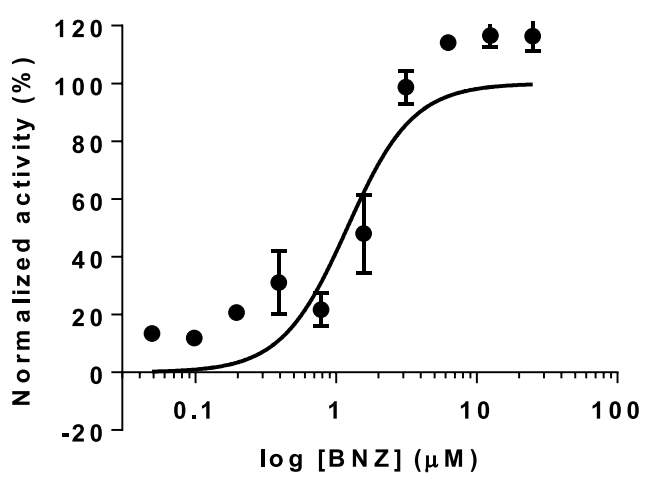

Hippeastrine

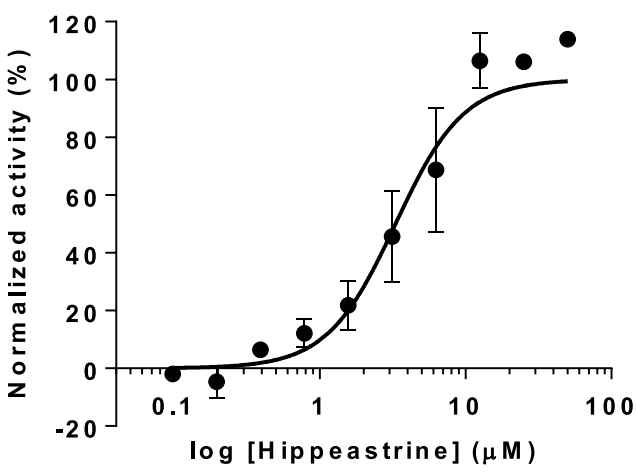

Fig. 5 Anti-amastigote dose response curves of hippeastrine and BNZ. Graphs represent mean results and SD of at least three replicates

Vero cells its $\mathrm{TC}_{50}$ to $\mathrm{IC}_{50}$ ratio was below that threshold and thus its anti-parasitic activity could not be considered specific (Table 1).

In contrast to all the aforementioned results, hippeastrine did show low toxicity against Vero cells $\left[\mathrm{TC}_{50}=45.99(6.32) \mu \mathrm{M}\right]$ and HepG2 cells $\left[\mathrm{TC}_{50}=128.1\right.$ (12.26) $\mu \mathrm{M}$ ], and complied with the SI window $>10$ against both cell lines (Table 1). It was the only compound that had a $\mathrm{SI}>10$ versus Vero cells $(\mathrm{SI}=12.67$; Table 1). Additionally, hippeastrine presented the highest SI against HepG2 cells $(\mathrm{SI}=35.29)$, with a $\mathrm{TC}_{50}$ value similar to that previously reported by Weniger et al. [43] $\left(\mathrm{TC}_{50}=40 \mu \mathrm{g} / \mathrm{ml}\right.$, i.e. $\left.126.85 \mu \mathrm{M}\right)$. Therefore, in a subsequent anti-amastigote biological assay we assessed whether hippeastrine anti- $T$. cruzi activity was indeed specific against this replicative form of the parasite. We found that the observed anti-amastigote activity $\left(\mathrm{IC}_{50}\right)$ was $3.31(0.39) \mu \mathrm{M}$, which was again within $5 \times$ that of the reference drug BNZ in the same assay $\left[\mathrm{IC}_{50}=1.2(0.22) \mu \mathrm{M}\right]$ (Fig. 5). Moreover, the corresponding SI for hippeastrine with respect to its antiamastigote activity will yet be $>10 \quad(\mathrm{SI}=13.89$ against Vero cells, and 38.69 against HepG2 cells).

Cytotoxicity results together with in vivo assays reported by Zhou et al. [38] may predict a low toxicity of hippeastrine in a future evaluation of its anti-T. cruzi activity in animal models. However, before performing in vivo studies, additional in vitro studies should be pursued to better validate this alkaloid. For example, assessing its effect on a T. cruzi CYP51 target [44], since this drug target has been invalidated in the clinic $[45,46]$, and identifying whether it can kill dormant parasite forms [47]. Moreover, it would be of interest to determine key in vitro pharmacokinetic (PK) parameters such as its solubility, permeability and clearance.

\section{Conclusions}

We identified one compound with specific anti-T. cruzi activity, upon the evaluation of nine alkaloids purified from extracts of different Narcissus species (family Amaryllidaceae) [16], proving that natural products are an interesting source to potentially identify new chemical structures for Chagas disease drug discovery. Our findings suggest that hippeastrine [17] is a relevant compound to be further studied. The analysis of its capacity to kill parasite dormant forms, and identification of its main target deserve further investigation in the future.

\section{Supplementary information}

Supplementary information accompanies this paper at https://doi. org/10.1186/s13071-020-04171-6.

Additional file 1: Figure S1. EIMS spectra of the nine compounds used in the study. Figure S2. 1 H NMR spectra of hippeastrine. Figure S3. BNZ and DTX dose-response curves. Both reference drugs were included in every assay as a control of drug inhibition. Anti-T. cruzi assays are represented by circles while Vero and HepG2 cell toxicity assays by squares and triangles, respectively.

\section{Abbreviations}

BNZ: benznidazole; NFX: nifurtimox; FDA: Food and Drug Administration; GC-MS: gas chromatography-mass spectrometry; NMR: nuclear magnetic resonance; DMEM: Dulbecco's Modified Eagle's Medium; P-S: penicillin-streptomycin; FBS: fetal bovine serum; DMSO: dimethyl sulfoxide; PBS: phosphatebuffered saline; CPRG: chlorophenol red- $\beta$-D-galactoside; SD: standard deviation; Sl: selectivity index.

\section{Acknowledgements}

Not applicable.

\section{Authors' contributions}

NMP, NCS, JB, MJP, JG and JAP conceptualized the study. NMP performed all biological assays. NCS helped with the assays. LTC and JB purified the alkaloids and provided the collection. MJP and JG provided funds. NMP and JAP wrote the article. All authors read and approved the final manuscript. 


\section{Funding}

We thank the support by the Departament d'Universitats i Recerca de la Generalitat de Catalunya, Spain (AGAUR; 2017SGR00924), and funding by the Instituto de Salud Carlos III RICET Network for Cooperative Research in Tropical Diseases (ISCIII; RD12/0018/0010) and FEDER. JAP was funded by a Juan de la Cierva - Incorporación contract from the Spanish Science Ministry. LTC and JB (UB research group 2017SGR604) thank CYTED (416RT0511) for financial support. MJP research is supported by the Ministry of Health, Government of Catalunya (PERIS 2016-2010 SLT008/18/00132). We acknowledge support from the Spanish Ministry of Science and Innovation through the "Centro de Excelencia Severo Ochoa 2019-2023" Program (CEX2018-000806-S), and support from the Generalitat de Catalunya through the CERCA Program.

\section{Availability of data and materials}

Data supporting the conclusions of this article are included within the article and its additional file. Data and materials can be made available upon reasonable request to the authors.

\section{Ethics approval and consent to participate}

Not applicable.

\section{Consent for publication}

Not applicable.

\section{Competing interests}

The authors declare that they have no competing interests.

\section{Author details}

${ }^{1}$ Barcelona Institute for Global Health (ISGlobal), Hospital Clínic - University of Barcelona, 08036 Barcelona, Spain. ${ }^{2}$ Departament de Biologia, Sanitat i Medi Ambient, Facultat de Farmàcia i Ciències de l'Alimentació, Universitat de Barcelona, 08028 Barcelona, Spain.

Received: 18 January 2020 Accepted: 4 June 2020

Published online: 10 June 2020

\section{References}

1. WHO. Chagas disease (American trypanosomiasis). https://www.who.int/ en/news-room/fact-sheets/detail/chagas-disease-(american-trypanosom iasis). Accessed 4 Mar 2020.

2. Pinazo MJ, Gascon J. Chagas disease: from Latin America to the world. Reports Parasitol. 2015;4:7-14

3. Prata A. Clinical and epidemiological aspects of Chagas disease. Lancet Infect Dis. 2001;1:92-100.

4. Alonso-Padilla J, Gállego M, Schijman AG, Gascon J. Molecular diagnostics for Chagas disease: up to date and novel methodologies. Expert Rev Mol Diagn. 2017;17:699-710.

5. Crespillo-Andujar C, Venanzi-Rullo E, López-Vélez R, Monge-Maillo B, Norman F, López-Polín A, et al. Safety profile of benznidazole in the treatment of chronic Chagas disease: experience of a referral centre and systematic literature review with meta-analysis. Drug Saf. 2018;41:1035-48.

6. Forsyth CJ, Hernandez S, Olmedo W, Abuhamidah A, Traina MI, Sanchez DR, et al. Safety profile of nifurtimox for treatment of Chagas disease in the United States. Clin Inf Dis. 2016;63:1056-62.

7. Pinazo MJ, Muñoz J, Posada E, López-Chejade P, Gállego M, Ayala E, et al. Tolerance of benznidazole in treatment of Chagas' disease in adults. Antimicrob Agents Chemother. 2010;54:4896-9.

8. Cimmino A, Masi M, Evidente M, Superchi S, Evidente A. Amaryllidaceae alkaloids: absolute configuration and biological activity. Chirality. 2017:29:486-99.

9. Izumi E, Ueda-Nakamura T, Dias Filho BP, Veiga Júnior VF, Nakamura CV. Natural products and Chagas' disease: a review of plant compounds studied for activity against Trypanosoma cruzi. Nat Prod Rep. 2011;28:809-23.

10. Zulfiqar B, Jones AJ, Sykes ML, Shelper TB, Davis RA, Avery VM. Screening a natural product-based library against kinetoplastid parasites. Molecules. 2017:22:1715.

11. Nair JJ, Bastida J, Viladomat F, van Staden J. Cytotoxic agents of the crinane series of Amaryllidaceae alkaloids. Nat Prod Commun. 2012;7:1677-88.
12. Presley CC, Krai P, Dalal S, Su Q, Cassera M, Goetz M, Kingston DGI. New potently bioactive alkaloids from Crinum erubescens. Bioorg Med Chem. 2016:24:5418-22

13. Sramek JJ, Frackiewicz EJ, Cutler NR. Review of the acetylcholinesterase inhibitor galanthamine. Expert Opin Investig Drugs. 2000;9:2393-402.

14. Tallini LR, de Andrade JP, Kaiser M, Viladomat F, Nair JJ, Zuanazzi JAS, et al. Alkaloid constituents of the Amaryllidaceae plant Amaryllis belladonna $\mathrm{L}$. Molecules. 2017;22:1437.

15. Buckner FS, Verlinde CL, La Flamme AC, Van Voorhis WC. Efficient technique for screening drugs for activity against Trypanosoma cruzi using parasites expressing beta-galactosidase. Antimicrob Agents Chemother. 1996:40:2592-7.

16. Bastida J, Lavilla R, Viladomat F. Chemical and biological aspects of Narcissus alkaloids. Alkaloids Chem Biol. 2006:63:87-179.

17. Almanza GR, Fernández JM, Wakori EWT, Viladomat F, Codina C. Alkaloids from Narcissus cv. salome. Phytochemistry. 1996:43:1375-8.

18. Berkov S, Osorio E, Viladomat F, Bastida J. Chemodiversity, chemotaxonomy and chemoecology of Amaryllidaceae alkaloids. Alkaloids Chem Biol. 2020;83:113-85.

19. de Andrade JP, Berkov S, Viladomat F, Codina C, Zuanazzi JAS, Bastida J. Alkaloids from Hippeastrum papilio. Molecules. 2011;16:7097-104.

20. Pigni NB, Ríos-Ruiz S, Martínez-Francés V, Nair JJ, Viladomat F, Codina C, et al. Alkaloids from Narcissus serotinus. J Nat Prod. 2012;75:1643-7.

21. Bettiol E, Samanovic M, Murkin AS, Raper J, Buckner F, Rodriguez A. Identification of three classes of heteroaromatic compounds with activity against intracellular Trypanosoma cruzi by chemical library screening. PLoS Negl Trop Dis. 2009;3:e384.

22. Peña I, Pilar Manzano M, Cantizani J, Kessler A, Alonso-Padilla J, Bardera $\mathrm{Al}$, et al. New compound sets identified from high throughput phenotypic screening against three kinetoplastid parasites: an open resource. Sci Rep. 2015;5:8771.

23. Zhang JH, Chung TD, Oldenburg KR. A simple statistical parameter for use in evaluation and validation of high throughput screening assays. J Biomol Screen. 1999;4:67-73.

24. Xiao Y, Yan W, Guo L, Meng C, Li B, Neves H, et al. Digitoxin synergizes with sorafenib to inhibit hepatocelluar carcinoma cell growth without inhibiting cell migration. Mol Med Rep. 2017;15:941-7.

25. Alonso-Padilla J, Cotillo I, Presa JL, Cantizani J, Peña I, Bardera Al, et al. Automated high-content assay for compounds selectively toxic to Trypanosoma cruzi in a myoblastic cell line. PLoS Negl Trop Dis. 2015;9:e0003493.

26. Khare S, Nagle AS, Biggart A, Lai YH, Liang F, Davis LC, et al. Proteasome inhibition for treatment of leishmaniasis. Chagas disease and sleeping sickness. Nature. 2016;537:229-33.

27. Mosca JD, Pitha PM. Transcriptional and posttranscriptional regulation of exogenous human beta interferon gene in simian cells defective in interferon synthesis. Mol Cell Biol. 1986:6:2279-83.

28. Machocho AK, Bastida J, Codina C, Viladomat F, Brun R, Chabra SC. Augustamine type alkaloids from Crinum kirkii. Phytochemistry. 2004;65:3143-9.

29. Osorio EJ, Berkov S, Brun R, Codina C, Viladomat F, Cabezas F, et al. In vitro antiprotozoal activity of alkaloids from Phaedranassa dubia (Amaryllidaceae). Phytochem Lett. 2010;3:161-3.

30. Nair JJ, Wilhelm A, Bonnet SL, van Staden J. Antibacterial constituents of the plant family Amaryllidaceae. Bioorg Med Chem Lett. 2017:27:4943-51.

31. Tallini LR, Osorio EH, Santos VDD, Borges WS, Kaiser M, Viladomat F, et al. Hippeastrum reticulatum (Amaryllidaceae): alkaloid profiling, biological activities and molecular docking. Molecules. 2017;22:2191.

32. Nair JJ, van Staden J. Cytotoxicity studies of lycorine alkaloids of the Amaryllidaceae. Nat Prod Commun. 2014;9:1193-210.

33. Machocho A, Chhabra SC, Viladomat F, Codina C, Bastida J. Alkaloids from Crinum stuhlmannii. Planta Med. 1998;64:679-80.

34. Herrera MR, Machocho AK, Brun R, Viladomat F, Codina C, Bastida J. Crinane and lycorane type alkaloids from Zephyranthes citrina. Planta Med. 2001;67:191-3.

35. de Andrade JP, Pigni NB, Torras-Claveria L, Berkov S, Codina C, Viladomat $F$, et al. Bioactive alkaloid extracts from Narcissus broussonetii: mass spectral studies. J Pharm Biomed Anal. 2012;70:13-25.

36. Franco CH, Alcantara LM, Chatelain E, Freitas-Junior L, Moraes CB. Drug discovery for Chagas disease: impact of different host cell lines on 
assay performance and hit compound selection. Trop Med Infect Dis. 2019:4:82.

37. He J, Qi WB, Wang L, Tian J, Jiao PR, Liu GQ, et al. Amaryllidaceae alkaloids inhibit nuclear-to-cytoplasmic export of ribonucleoprotein (RNP) complex of highly pathogenic avian influenza virus H5N1. Influenza Other Respir Viruses. 2013;7:922-31.

38. Zhou T, Tan L, Cederquist GY, Fan Y, Hartley BJ, Mukherjee S, et al. Highcontent screening in hPSC-neural progenitors identifies drug candidates that inhibit Zika virus infection in fetal-like organoids and adult brain. Cell Stem Cell. 2017;21 (274-83):e5.

39. Evidente A, Andolfi A, Abou-donia AH, Touema SM, Hammoda HM, Shawky E, et al. (-)-Amarbellisine, a lycorine-type alkaloid from Amaryllis belladonna L. growing in Egypt. Phytochemistry. 2004;65:2113-8.

40. Cedrón JC, Gutiérrez D, Flores N, Ravelo ÁG, Estévez-Braun A. Preparation and antimalarial activity of semisynthetic lycorenine derivatives. Eur J Med Chem. 2013;63:722-30
41. Choi JM, Oh SJ, Lee SY, Im JH, Oh JM, Ryu CS, et al. HepG2 cells as an in vitro model for evaluation of cytochrome P450 induction by xenobiotics. Arch Pharm Res. 2015;38:691-704.

42. Crouch SP, Kozlowski R, Slater KJ, Fletcher J. The use of ATP bioluminescence as a measure of cell proliferation and cytotoxicity. J Immunol Methods. 1993;160:81-8.

43. Weniger B, Italiano L, Beck JP, Bastida J, Bergoñon S, Codina C, et al. Cytotoxic activity of Amaryllidaceae alkaloids. Planta Med. 1995;61:77-9.

44. Riley J, Brand S, Voice M, Caballero I, Calvo D, Read KD. Development of a fluorescence-based Trypanosoma cruzi CYP51 inhibition assay for effective compound triaging in drug discovery programmes for Chagas disease. PLos Neg Trop Dis. 2015;9:e0004014.

45. Molina I, Gómez i Prat J, Salvador F, Treviño B, Sulleiro E, Serre N, et al. Randomized trial of posaconazole and benznidazole for chronic Chagas' disease. N Eng J Med. 2014;370:1899-908.

46. Morillo CA, Waskin H, Sosa-Estani S, Del Carmen Bangher M, Cuneo C, Milesi R, et al. Benznidazole and posaconazole in eliminating parasites in asymptomatic T cruzi carriers: the STOP-CHAGAS trial. J Am Coll Cardiol. 2017;69:939-47.

47. Barrett MP, Kyle DE, Sibley LD, Radke JB, Tarleton RL. Protozoan persisterlike cells and drug treatment failure. Nat Rev Microbiol. 2019;17:607-20.

\section{Publisher's Note}

Springer Nature remains neutral with regard to jurisdictional claims in published maps and institutional affiliations. 